\title{
STUDENT'S PERSPECTIVES ON THESIS WRITING IN ENGLISH ACADEMIC CULTURE
}

\section{Dewi Novita $^{1}$ \\ (Pend. Bahasa Inggris, FKIP Universitas Tanjungpura Pontianak)}

\begin{abstract}
Thesis writing is important in higher education because it shows the students' ability in doing research and producing written academic results. Generally, it is assume that university students are educated people and therefore have an ability to produce a thesis. Yet, this is not always as easy as it seems. For students studying in English academic culture, for example, thesis writing brings two challenges, First, a challenge of writing in a language that is not their own, English. Second, a challenge of producing written work in a new cultural context, that is English academic culture. These challenges often cause great difficulties in producing the thesis for the Indonesian students.
\end{abstract}

Key Word: Perspectives, Indonesian Students, Thesis, English Academic Culture.

\section{A. BACKGROUND}

Much research has been conducted on English study and cross cultural understanding (Ballard, 1990, 1995; Ballard and Clanchy, 1991; Fox, 1990; Barker et al, 1991; Gallois and Callan, 1997; Hall and Hall, 2000; Hofstede, 1998; Moui, 2000; Spizzica, 2004). However, although these studies describe the challenges of the new language and culture for students, a little attention has been given to the students' own perspective of the challenges and how they tackle those challenges to succeed in their studies.

It is know from many researches that there is an interaction between students' culture and their experiences in English academic culture. Most research suggests that the thesis writing in the university does not only represent students' ability in the research and academic writing, but also the language, culture and attitude of the academic society where the thesis is

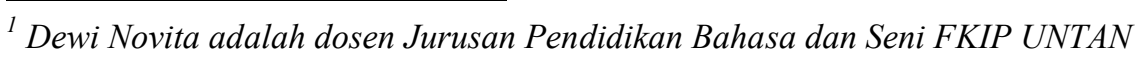


produced (Ballard, 1995; Ballard and Clanchy 1990, 1991; Connor and Kaplan, 1987; Barker et al 1991; Biggs, 1997; Clyne, 1992; Gudykunst, 1998; Duszak, 1994).

In general, the difficulties of thesis writing for the students concern aspects such as critical thinking, linear ideas and originality (Ballard and Clanchy, 1990, 1991; Ballard, 1985; Biggs, 1997; Gudykunst, 1998; Connor and Kaplan, 1987).

Critical thinking is considered difficult because of several reasons. First of all, it challenges most students' previous experiences in academic education. Critical thinking, in English culture, emphasizes judgment presented in the form of reasoned argument (Ballad and Clanchy, 1990). In thesis writing, for example, critical thinking means students present experts' ideas by putting judgment and argument on the value of the idea. The action of judging and arguing, unfortunately, do not have much value to most students with their own culture background. In fact, the actions are considered inappropriate because they show no respect to the knowledge and the position of the experts (Ballard and Clanchy, 1991). In addition, critical thinking is difficult for most students because the act of voicing arguments contradicts the concept of harmony that most of the students value in their own academic culture. Moreover, as many of the students are from horizontal collectivist societies, the action of standing out and voicing arguments can be quite difficult, as described in the saying, "the nail that sticks out gets hammered down" (Gudykunst, 1998).

Similar to the difficulties with critical thinking, the problem that most students have with producing linear ideas is also mainly cultural. According to Kaplan (cited in Ballard and Clanchy, 1991), most Asian students with their Asian culture had circular pattern of thinking. In this pattern of thinking, the writing is characterized by indirectness - ideas that circle around the topic ideas of the writing. The writing form can look like an upside down pyramid where plenty of background information that decorates the writing is at the top, and at the bottom is the main topic of the writing. With this pattern of thinking, it is difficult for these students to understand and apply the concept of being direct. Next, the problem is also linked to the context of culture that the students have. For students with collectivist culture, the context of the culture tends to be high, the direct and clear ideas on the writing, therefore is 
not necessary. The students are educated to believe that their readers have adequate knowledge so that giving explicit and direct description on the writing is considered inappropriate and underestimating the readers' knowledge (Hall, 2000)

The concept of originality mainly relates to paraphrasing ideas in the thesis writing. This is considered an important act of writing in English academic culture. For the students, however, this concept may be difficult to apply. There can be a language problem that leads the students to quote the exact wording of the text rather than summarizing it in their own words. As Ballard and Clanchy (1990: 108) state:

Much of the intellectual frustration and feeling of incompetence that the students have come from problems of thinking in English. They know the statements they can make in English are so much simplified and naïve than their thinking in their own language.

There are also cultural influences that make the paraphrasing difficult for the students. In Indonesian culture, for example, experts' ideas are considered as a set of values that are the established truth. Therefore, to paraphrase the ideas would be considered not necessary.

As paraphrasing is considered difficult to perform, direct quotation of the resources become the most preferred option. However, this activity also brings problem to the students because the way quoting is done in the students' own academic culture is very different from English academic culture. For example, in English academic culture, the quotation is accompanied by complete referencing of the author and other necessary information from where the ideas are taken. The act of providing the information in English academic culture is important in order to acknowledge the private property of ideas of an individual. In most Asian academic culture, including Indonesian, however, referencing may not be that important because the ideas are considered public property that any member of the society can use directly. In addition, there is also a high context of culture that indicates shared values in the society so that the act of giving references is unnecessary (Ballard, 1995). 


\section{B. STUDENTS' PERCEPTIONS OF THEIR STRATEGIES TO OVERCOME THE}

\section{DIFFICULTIES}

Ballard and Clanchy (1990) argue that it is not easy to suggest fixed strategies to overcome difficulties that student have because the students are unique as individuals and often approach the difficulties with strategies which may not be the same as the other students. Yet, it is still worth presenting some strategies, which have been found successful to help to give examples and perspectives in dealing with the difficulties.

From the literature presented by many researchers, the strategies can be classified into two parts: strategies that the students can do independently and strategies that involve other parties (i.e., supervisor, friends, academic advisor, etc).

For the strategies that the students can mostly do independently, Ballard and Clanchy (1990) suggest the students practice their writing more frequently so that it is easier to see the progress of their language and writing skills. In addition, it is advised that the students recognize and understand the culture influence on their writing and try to adapt to the new values that are used in thesis writing in English academic tradition.

Besides applying the self-oriented approaches, it is suggested that the students actively seek help from others, including their supervisor, colleagues, friends, academic advisor and the university support services (language centre, etc). Through discussion with these people, the students can develop thorough and mutual cross culture understanding and also gain new insight about their writing. Moreover, discussion, especially with supervisors, can also help both parties to recognize the weaknesses and learn together to improve the writing.

\section{Reflection on Academic Culture Differences}

There are three points being analyzed here on the reflection on academic culture differences, namely students' understanding of their supervisor's expectation in their thesis writing, the communication between the students and their supervisor and the comparative analysis on the academic differences between English and Indonesian. 
a. The Students' Understanding of the Supervisor's Expectation in their Thesis Writing

Supervisor's expectation of the students in their thesis writing is the most important thing that the students should know and understand completely. That is because the whole process of thesis writing depends on how much they can fulfill this expectation. In this paper, the exploration of the students' understanding of the supervisor's expectation of their thesis writing is with regard to the process of making sentences and paragraphs on the thesis. In general, students have good idea of what is expected from them in thesis writing. They may have been told by their supervisors about the expectation or somehow have known about it from their friends, books or experiences in their study. In this case the perceived expectations of the supervisors can be categorized as critical thinking, being direct and organized, using the appropriate reference system and punctuation.

b. Critical Thinking

Student learning in English academic culture believed that the supervisors expected them to think critically. Critical thinking here is related to independence, analysis and argument.

As an act of independence, critical thinking allows the students to create ideas that are different from others. The independence also allows ideas that do not confirm the experts, in thus the ideas can range from agreeing, disagreeing, believing, disbelieving, etc. In other words, the independence gives a freedom to voice the self thinking on the writing.

Next, critical thinking was defined as an analysis process which includes two things: questioning the elements of the thing and the reason for its occurrence. In the thesis writing, the analysis leads the students to present ideas of experts with their own constructions and interpretations. In other words, the analysis made the ideas in the writing have a soul that contain the students bias and tacit knowledge of the matter, which in turn, makes the writing an active process of thinking.

Finally, critical thinking is defined by word argument. It is suggested that critical thinking in the thesis is in the form of arguments that the students write, especially when citing ideas from the literature. In giving arguments, the students should discuss pros and cons of the ideas from a reasoned point 
of view. In summary, the argument is an actual outcome of being independent and analytic in the critical thinking process.

From the explanation above, it can be concluded that the concept of critical thinking in the thesis writing include actions of analyzing, questioning, evaluating and judging a subject which is presented in a persuasive and reasoned argument.

c. Direct and Organized

Supervisor expected that in thesis writing the students can be direct and organized. These terms mean that the students should write sentences and paragraphs which are to the point and relevant. Being direct and organized also oblige the students to be efficient in terms of words and effective in meaning, or in other words the thesis is free from any circumlocution of ideas, irrelevance, wordiness or repetition.

d. Originality - Using Appropriate Referencing System

The third expectation of the supervisor on thesis writing is the originality in referencing. Being original also means that the students write ideas from other people by acknowledging the resource completely. In this case the respect of copyright of other's idea is high. However, with the limited ability in paraphrasing might make the students produce ideas without even changing the wording or providing adequate analysis of the ideas. In short, although the students know and have understood the concept of originality, they may find it a challenge to fulfill.

\section{e. Punctuation}

The correct use of punctuation is also expected by the supervisor on thesis writing in English academic culture. It is because clear connection of ideas in the sentences is crucial in the thesis. Furthermore, there is a strong connection between directness and appropriate use of punctuation, as the punctuation makes the meaning of the thesis direct. However, problem might occur due to differences in the use of punctuation symbols in Indonesian language and English. 
2. The Communication between the Students and the Supervisors

Communication is crucial for both students and supervisors in the process of writing the thesis. With communication, the supervisors can monitor the progress of the students while at the same time the students get the supervision they need for the next stage of thesis writing. This supervision is often in form of feedback on their writing drafts.

There are four feedback foci that students may have during the whole process of their communication with the supervisors. These include feedback on referencing, critical analysis, linear pattern of thinking and logic. In English academic culture, the supervisors' feedback asked the students to be direct and critical which fit to their expectation. It is assume that there is a gap between the students' knowledge of the expectation and their writing outcomes. In other words, students do face problems fulfilling the expectations. However, this may indicate the limitation in the students' writing, it is still a positive finding for both students and supervisors as knowing the problems at early stage of supervision would give the students more chance for early assistance from their supervisor. Finally, the finding also shows that the students and the supervisors have mutual interaction on the process of thesis writing.

\section{Academic Culture Differences}

During the process of thesis writing, the students may experience some aspects of culture that are different (between their own culture and English academic culture).

First is connectedness of ideas in the writing. In English academic culture, the ideas of the writing are organized and connected. For example, the introduction and the supporting sentences of a paragraph of the thesis are related to one another and form a solid idea. Moreover, connectedness also means that the students should provide supporting evidence in their writing. For instance, when writing a topic on the use of certain media to improve a teaching, the student should mention everything related to the media and the teaching and also to what extend the teaching can be improved.

Second of all, the proportion of information described in the writing is also different between English academic culture and the students own culture. In English academic culture, clear and complete explanation is necessary for 
the readers in their writing. In other words, the author has to supply detailed explanation. $\mathrm{N}$ the students own culture, however, complete explanation is not necessary. The reason for this is because the assumption that readers have shared knowledge, therefore providing detailed information is just like insulting the readers' intelligence.

Next, the difference between English academic culture and the students own culture is found in the respect of individual ideas. English academic culture requires a complete referencing system, where acknowledgement of the source being sued in the writing is crucial. In the students own culture it is not that specific.

Moreover, the difference in academic culture between English and the students lies mostly in the way information is presented. In English academic culture, the information is presented in critical and persuasive analysis. In the students own culture this persuasive analysis is not encouraged. This is because keeping harmony is more appreciated. Therefore triggering conflict should be avoided.

In conclusion, there are several characteristics that are different between English academic culture and the students own culture. It is interesting to note how much the students can understand the differences when they acquire English language and its academic culture. Their analyses on the differences went deeper in the way they perceive information presented in their process of thesis writing.

4. Difficulties in Writing a Thesis

\subsection{Culture}

Critical analysis is considered difficult because the students have different cultural perceptions. For the students, it is not because there is a problem of not knowing the concept of being critical, but it is more in a way that the students are not accustom to it. It is often happen that the students' unwillingness to be critical because they thought it would go against the concept of being good and polite or the directness might trigger a conflict. 


\subsection{Language}

The difficulty with language, for the students in writing thesis was perceived as poor mastery of vocabulary. It is difficult to find equivalent words to describe the ideas, aspecially terminology used in the field. The problem might get worse when the students need to paraphrase a citation from literature.

\subsection{Personality}

The students may face difficulties in their thesis writing in academic culture due to their personality traits. This may become the biggest problems in the students' adjustment to produce a good thesis writing in English academic culture. The traits include the students' attitude toward making mistake and correction and their level of confidence.

The lack of confidence in writing performance may affect the students' confidence to success in writing a thesis in English academic culture. In Asian academic tradition, it is generally assume that the students should be humble, while in English academic culture the students should be critical. It is not easy for the students to put themselves in different position. It takes some times for the students to build up confidence that is crucial to succeed in their writing. When the personality has changed, the students will be able to fit in the English academic culture.

It is indicated that the English academic tradition demands different attitude from the students own academic traditions in term of personality. However, having found this difference and also experience the difficulty with the impact of the difference, the students should not give up. The students should be motivated to tackle the difficulties, or in other words, they should approach the difficulties with a positive attitude in order to find solutions they need to succeed in their thesis writing.

In general, the comprehensive ideas about the perceived expectations of supervisors in thesis writing are very important. In term of culture, the difficulties were mostly in critical analysis, directness and logical organization of ideas. With language, on the other hand, the problem is mainly to do with poor vocabulary mastery. Finally, the difficulty with personality relates to the attitudes toward making mistakes and corrections in the thesis writing. 


\section{Tackling the Challenges of Thesis Writing}

The analysis of students' strategies to tackle the difficulties of thesis writing is important because the ideas will help students to be success in their thesis writing. It is also important to identify the students' qualities that made the successful in their thesis writing i.e. finishing the thesis, submitting it to their supervisor and accepted to be examined in the thesis examination.

\subsection{Strategies to Overcome the Difficulties}

In general, there are two strategies that students can use to overcome the difficulties in writing a thesis: self analysis and active interaction with the supervisor in the process of thesis guidance.

Self analysis, for most students, was undertaken in order to examine themselves, their own culture and education's perceptions of the English academic culture. Self analysis helped the students to see the differences as merely challenges that they can tackle. It is believe that it takes some time for the students to understand and analyze themselves. During this period, the students learn to see the problems and accept the weaknesses. Later, the students will be able to see the problems more clearly and positively.

Once the students understood themselves a lot better, they approach other people for helps they need to tackle the problems in their thesis writing. The students should take an active role in asking to supervisors for encouragement they need in writing. With this action, the students will realize that they were not the same person as they were before. They are not passive instead they are active for help and come and get it themselves. The action of being active in this matter changes their role. They become actively approach their colleagues, friends and university support service (language centre) for the help they need. In short, the students' effort in tackling their problems in thesis writing, somehow, will change their role and attitude from accepting and passive to more active in seeking help from others.

\subsection{The meaning of Solving Problems of Thesis Writing}

Students that believe challenges should be tackled in the process of thesis writing will lead the students into success in finishing their thesis. There are two things that are valued in this matter. First, it is important that students use the word challenges instead of difficulties on the problems of thesis writing. 
There is a positive attitude toward the word challenge rather than the word difficulties which will make the students had positive thinking towards the challenges. This positive thinking is an important factor that creates an attitude of success for the students. By the use of the word challenges, the students will also show that they have a strong belief in their ability to tackle the challenges. This attitude is the one that build up the students' confidence to succeed.

\subsection{The Motivation to succeed in Thesis Writing}

Students can be motivated to succeed in thesis writing because of external or internal factors. Some of the students may be motivated externally by their supervisor, family, colleagues, and friends. Some others may have more internal or self-motivation to succeed. It is interesting to point out that students who are from collectivist value somehow may have strong individual motivation. The students may have pride in themselves and need other to recognize it. This, in return, makes achievement in thesis writing crucial to the students. Another idea that lead to motivation is the necessity for the students to create an image of good students and viewed as intelligent people that are fully motivated and have broad understanding of the meaning of success within themselves.

\subsection{Changes and Attitude toward the Changes}

When the students succeed in tackling the challenges of writing the thesis in English academic culture, they were then considered as having made changes in their writing, that is, to suit the pattern of the English tradition. The changes are meaningful for the students as they learned to adjust their culture, language and personality to the English academic way.

In culture, the students will learn to switch the circular pattern of thinking and harmony values to a direct and critical pattern of thinking. These changes may mean that their thesis is more to the point in ideas, brave in voicing and argument and deep in analysis.

In language, the students' thesis changed in terms of appropriate use of a referencing system. This change symbolized the revelation of respect of individuality for the students and shows awareness and appreciation of copyright of ideas. In the process, the students will also realize that they have 
improved their vocabulary mastery which is shown from their command in paraphrasing other people's opinion in their own wordings.

The most important change that the student may have in the process of thesis writing is the personality. The changes include an acceptance of criticism, being open minded, independent in opinion, confident, an appreciation of relativity and respect of differences.

Some student may also experience that they change from being reluctant to being more independent in giving opinion. This change is the most difficult change they may have throughout their thesis writing. It is because it is not in the students' nature to think independently. It is believed that the students who are bound by collectivist values of uniformity of ideas have a less tendency to voicing their own ideas. Yet, from their study in English academic culture, they may learn and change to be freer in stating their own ideas without feeling worried about the collectivist opinion.

The best change that the student may experience in the process of thesis writing is to believe in relativity. In Asian academic culture, everything can be perceived as black or white; there is only one single truth. For example, the student may commit to the idea that a method given by an expert must work in any context. Yet, in English academic culture, the students learn that the concept is not always true and that everything is relative. The students learn to see the fact before accepting any ideas. Given the same example, in English academic culture $t$ he students would suggest that the method would not necessarily work in every context because the situation could be different. In short, the change that the students have is by looking at a new perspective of judging thing from their study in English academic culture.

Finally, student may change from believing in a collectivist valuerespecting harmony of opinion to a more individualistic value-respecting different opinion. This change may happen as the students began to accept the individualistic values on their new academic life. It may difficult for them to have a disagreement on ideas with others, especially to their supervisors. It is like taking the supervisors' face. But after a while, the students will understand that in English academic culture and relationship to point out arguments is not bad as there is a respect for differences. From this experience, the students will be able to share ideas and appreciate different opinions. 
The explanation above it can be concluded that the process of writing a thesis in English academic culture and tackling the difficulties on the writing may make the students change in culture, language and personality. In culture, the students would make their thesis more critical, direct and deeper in analysis. In language, the students will make improvements in their vocabulary mastery and the use of referencing system. Finally, in personality, the students will be able to accept criticism, be open minded, independent in opinion, confident, appreciate relativity and respect differences. These personality changes were considered as the most difficult yet will be the best changes that will happened to the students.

\subsection{Suggestion for Supervisors and academic advisor}

In relation to the supervisors and academic advisors, there is a question of how active the supervisor or the academic advisor role is in the process of change that the students go through in English academic culture. The students may learn to see the academic culture differences by themselves when they perform an active self analysis of their situation. However, the supervisor and academic advisor helps is crucial in the process of leading the student to recognize English academic culture which then they analyze and compare with their own culture. Discussions on the problems face by the students in English academic writing will build a mutual understanding on the matter. Somehow, if there is a change that the supervisor or academic advisor see earlier, the students self analysis will soon be developed.

\section{CONCLUSIONS}

There are aspects that are found different between English academic thesis writing and students own culture in terms of connectedness of ideas, proportion of information being described in the thesis, respect for individual's ideas, proportion of information being described in the thesis, respect for individual's ideas and the way the information is presented. These differences may cause difficulties for the students to fulfill the expectation of the supervisors on their thesis writing especially in being critical, direct, organized and original. It is significant to know that the students may show deep understanding of both academic cultures they have experienced. It is also interesting to point out that students' awareness of cultural reasons underlying the difficulties they experience in English academic culture help them in the process of tackling the difficulties. Good support from the 
supervisors, academic advisor, and other external parties will bring mutual interaction that makes it easier for the students to tackle the problems.

There are three factors that are related to students' difficulties in thesis writing: culture, language and personality. With culture, the students may find thesis writing is difficult in terms of critical analysis, directness and logical organization of ideas. With language, the difficulties are mostly with appropriate use of words for referencing. Lastly, the personality difficulties are the attitudes toward making mistakes and corrections and the level of confidence. These are perhaps the most difficult for them. From the whole analysis of these three factors, it can be concluded that the difficulties generally can occur because the students are not familiar with the English academic traditions. The analysis also explores the students' strategies to overcome the difficulties, which includes self analysis and active interaction with other people.

\section{REFERENCES}

Ballard, B. \& Clanchy J. (1990). Study Abroad: A Manual for Asian Students. Malaysia: Longman.

Ballard, B \& Clanchy J. (1991). Teaching Students from Overseas. Melbourne: Longman Cheshire.

Ballard, B. (1995). Some issues in Teaching International Students. In L. Conrad \& L. Philips (Eds), Reaching More Students. Queensland: Griffith Institute for Higher Education.

Barker, M., Child, C., Gallois, C., Jones E. \& Callan V. (1991) Difficulties of Overseas students in Social and Academic Situations. Australian Journal of Psychology, 43 (2).

Biggs, J.B. (1997). Teaching across and within Cultures: The Issue of International Studnets. In R. Murray-Harvey and H. C. Silins (Eds). Learning and Teaching in Higher Education: Advancing International Perspectives, Adelaide: Flinders Press.

Clyne, M. (1982). Modes of Communication and Culture. In H. Bock and J. Gassin. (Eds), Papers from the Conference, Communication at University: Purpose, process and product. Melbourne: La Trobe University. 
Duszak, A. (1994) Academic Discourse and Intellectual Styles. Journal of Pragmatics: An Interdisciplinary Monthly of Language Studies.

Fox, H. (1990). Listening to te World: Cultural Issue in Academic Writing. National Council of Teacher of English, United States of America.

Gallois, C.A. \& Callan V. (1997) Communication and Culture. A Guide for Practice. John Wiley and Sons, Chichester England.

Gudykunst, W.B. (1998). Individualistics and Collectivistics Perspectives of Communication: An Introduction (Extract). International Journal of Intercultural Relations.

Hall, E.T. (2000). Beyond Culture. Ney Work: Doubleday.

Hall, E.T., \& Hall, M.R. (1990). Understanding Cultural Differences: German, French and Americans. Yarmouth. Maine: Intercultural Press.

Hofstede, G. (1998). Culture's Consequences: International Differences in Work Related Values. Sage Publications.

Connor, U. \& Kaplan, R.B. (1987). Writing Across Languages: Analysis of L2 tetx. Addison-Wesley Publishing Company, Inc. USA.

Lincoln, Y. S., \& Guba, E. G. (1985). Naturalistic Inquiry. Beverly Hills. CA: Sage.

Muoi, V. N. (2000). Different Communication Process: Journal of Vietnamese Studies.

Spizzica, M. (2004). Cultural Differences Within "Western" and "Eastern" Eduation. In Golebiowski, Z. \& H. Brolan (Eds). Academic Communication Across Discipline and Cultures. Melbourne: VUT.

Ting-Toomey, S. (1984). Qualitative Research: An Overview. In W.B.

Gudykunst \& Y. Y. Kim (Eds). Methods for Intercultural Communication Research. Beverly Hills, CA: Sage 